\title{
Microbes and Health
}

ISSN: 2226-0 153 (Print) 2305-3542 (Online)

http://journal.bsvmph.org/

Microbes and Health, January 2015, 4(1): 25-28

DOI: $10.3329 / \mathrm{mh} . v 4 \mathrm{i} 1.23096$

\section{ORIGINAL RESEARCH ARTICLE}

\section{Screening for Escherichia coli 0157 isolates of bovine origin}

\author{
Md. Ali Hossain*, Nigarin Sultana and Selina Akter
}

Department of Microbiology, Jessore University of Science and Technology, Jessore-7408, Bangladesh.

*Corresponding author's email: md.alihossain.j@gmail.com

\begin{abstract}
Escherichia coli $\mathrm{O} 157$ was serologically identified from isolated E. coli of bovine origin in Jessore, Bangladesh. Pre-enrichment and enrichment media were used in isolating the enteric bacteria and swip off transient soil microbes. Differential and selective culrure techniques were used and biochemical tests were performed to identify E. coli strains. Slide agglutination test with antisera against O157 anigens were performed on biochemically identified E. coli strains. A total of 15 samples consisting freshly deficated cowdung, compost and soil near cow shed were assessed and among them 24 isolates were identified as E. coli. Twelve E. coli isolates isolated from eight samples gave agglutination with anti O157 antisera. Presence of E. coli O157 isolates was higher in composts and soils compared to fresh cowdung. This result indicates the strain's adaptive and survival potential in environmental condition and raises potential public health concerns in handling such animal waste and its derivatives.
\end{abstract}

Key Words: Escherichia coli O157, Cattle, bovine origin, Cow dung, Risk assessment, Prevalence rate.

(C) 2015 Microbes and Health. All rights reserved

\section{Introduction}

E. coli $\mathrm{O} 157$ is an enterohemorrhagic strain of the bacterium Escherichia coli that causes illness through food (Karch et al., 2005) often associated with hemorrhagic colitis and hemolytic uremic syndrome (Yekta et al., 2011). Ruminants are the important reservoir of E. coli $\mathrm{O} 157$ (Yekta et al., 2011) and cattle remains one of the main reservoirs of Shiga toxin producing E. coli O157 (STEC) (Eppinger et $a l ., 2011)$. Indistinguishable subtypes of E. coli $\mathrm{O} 157$ also found to present in the goat as well (Lengacher et al., 2010). The virulence factors detected in E. coli $\mathrm{O} 157$ strains isolated from the faces of buffaloes (Seker et al., 2010). The red deer in south-central Spain has been found to be the potential reservoir hosts of sorbitol-fermenting $E$. coli $\mathrm{O} 157$ strains, which are emerging causes of hemolytic uremic syndrome in Europe (Diaz et al., 2011).

Cow dung has indigenously been used for long specially in the region of Indian sub continent. It is used as a cooking fuel, sanitizing cleanser, construction material, insulation, and waterproofing for walls and floors in rural houses. An understanding of the use of cow dung and urine by the rural population can illustrate the indigenous knowledge and cultural symbol in religious worship (Nripendra, 2012). Even in modern age, it is the raw-material for producing organic compost and generating electricity through biogas plant. Even the ash formed from the burning of dung as a fuel can be used as a cleaning agent for household utensils. Clearly, the use of cow dung as indigenous resources provides a stark contrast to the modern hi-tech advancement as well as to issues of public health concepts. Handling of cow dung, during cleaning of sheds, making dung cakes to be used as fuel and swiping of floors used i.e., for drying of grains, pose threat of direct contamination of handler and food. E. coli $\mathrm{O} 157$ in manure-amended soil is considered to be an important factor for the likelihood of crop contamination (van Overbeek et al., 2010). Draining of shed waste to water sources also let the strain to get access to the aquatic system and food chain of the ecosystem (Arthur et al., 2010).. However, contamination of water also threatens the risk of E. coli $\mathrm{O} 157$ borne UTI and HUS (Tarr, 1995; Fischer Walker et al., 2012) as the rural people uses natural water body for bathing and other sanitation practices.

Three major virulence factors of this pathogen have been identified including Shiga toxins, a pathogenicity island called the locus of enterocyte effacement, and an F-like plasmid, pO157 (Lim et al., 2010) which is responsible for The $\mathrm{O}$ (capsular/outer membrane polysaccharide) antigens present on the surface of E. coli $\mathrm{O} 157$ strains. Cattle can harbour the bacteria in the gastrointestinal tract without showing any clinical symptoms (Vande Walle et al., 2011). So physical examination or disease state of ruminants does merely correlates with its carriage of deadly E. coli O157. Systemic immunization of cattle with intimin and EspB could be a feasible strategy to reduce E. coli $\mathrm{O} 157$ faecal shedding in cattle (Vilte et al., 2011). Bacteriophages may mitigate E. coli $\mathrm{O} 157$ in cattle and their environment (Stanford et al., 2010) and chitosan microparticles to feed may decrease its shedding (Jeong et al., 2011). Alteration of the gastrointestinal tract through manipulation of cattle diets has also been proposed as a preharvest control measure (Cernicchiaro et al., 2010), but all these measures hence unpractical for developing countries specially to the rural remote communities.

\section{Materials and Methods}

\section{Sample collection}

Four types of samples were collected during the study period: freshly defecated cow dung -hard type (FCD-H), freshly defecated cow dungsoft type (FCD-S), composting cow dung (CCD) and cow shade soil (SCS). A total of 15 samples were collected from three sites, i.e., from Am-bot-tola village area on 24 November, 2013, from Arabpur area on 19 April, 2014 and from Chowgacha area on 5 May, 2014 under Jessore district of Bangladesh.

\section{Pre-enrichment and Enrichment}

Approximately $1.0 \mathrm{~g}$ of sample was inoculated in pre-enrichment media and, incubated for four to five hours at room temperature. Hundred $\mu 1$ of pre-enrichment culture media were inoculated in $10 \mathrm{ml}$ 
of enrichment media and incubated at $37^{\circ} \mathrm{C}$ for overnight. Both the media has been designed and practiced in our laboratory; composition has been given in supplementary Table 1 .

\section{Culture isolation method}

The enrichment broth sampling media were streaked on MacConkey agar plate. It was incubated at $37^{\circ} \mathrm{C}$ for overnight. Pink (lactose fermentor) or colorless (lactos non-fermentor) medium size single colonies were isolated.. Isolated colonies were picked and subcultured on MacConkey agar plate again to obtain and maintain pure cultures of isolates and then stored for further identification. To observe the colony characteristics on differential and selective media, Eosin Methylene Blue (EMB) agar media and Xylose Lysine Deoxycholate (XLD) agar medium was used (Cheesbrough, 1985).

\section{Identification by biochemical test}

Biochemical characterization was performed to identify the isolates. Oxidase test, Catalase test, Citrate utilization test, Triple sugar iron (TSI) test, Motility indole urea (MIU) test, Methyl red test, VogesProskauer test and finally MUG test was performed to identify the bacterial isolate (Cheesbrough, 1985).

\section{Screening for Escherichia coli 0157 (Latex slide agglutination test)}

Latex slide agglutination test determines specific organism (such as $E$. coli $\mathrm{O} 157)$ by sensitized latex reagent containing antiserum against $\mathrm{O} 157$ antigen. The sensitized latex reagent containing antiserum has been purchased from Denka Seiken Co., Ltd. 3-4-2 Nhonbashikaybacho, Chuo-ku, Tokyo, Japan. One drop of normal saline water was taken on a sterile slide. Overnight culture of the test isolate was picked by a sterile wire loop and inoculated into the normal saline and prepared a homogenous suspension smear. One loopful of the sensitized latex reagent containing antiserum was added on the smear. The O (capsular/ outer membrane polysaccharide) antigens present on the surface of $E$. coli strains cross react with the antiserum present in the latex reagent and form clots of agglutination (Chapman, 1989) (Fig. 1).

\section{Test for Haemolysin}

The isolates were subcultured onto $5 \%$ blood agar plates and observed for haemolysis after incubation at $37^{\circ} \mathrm{C}$ for $24 \mathrm{~h}$.

\section{Results}

Identification of bacterial isolates by colony characteristics and biochemical tests

Observing the colony characteristics, most of the isolates were presumably identified as E. coli. Detail colony morphology on MacConkey agar media, xylose lysine deoxycholate agar and eosin methylene blue agar media of the 40 isolates (13 isolates from six samples of FCD-H, nine isolates from three samples of FCD-S, nine isolates from three samples of $\mathrm{CCD}$ and nine isolates from three samples of SCS).

Among 40 isolates 38 isolates were given oxidase negative result, though all of the isolates were catalase positive. Oxidase positive isolates were discarded. In citrate utilization tests, 14 isolates turn the media green to blue on Simmon's Citrate Agar media indicating positive result and thus again discarded. Among the rest 24 isolates 23 isolates were given yellow slant, red butt, gas produced, and no $\mathrm{H}_{2} \mathrm{~S}$ produced, only one isolates were given red slant, red butt, gas produced in TSI slant tube. All of the isolates were motile, urease negative as found in MIU tube except one. Hence the 22 isolates remained were indole positive as well as MR positive. These isolates were also cultured on MUG media and showed positive for 21 isolates. Among 24 isolates, 12 isolates were slide agglutination positive and all isolates were gamma haemolytic (no hemolysis) as observed in haemolysin test.
Table-1: Composition of Pre-enrichment and Enrichment media.

\begin{tabular}{|l|l|}
\hline $\begin{array}{l}\text { Pre-enrichment } \\
\text { media }\end{array}$ & Peptone $2.5 \mathrm{~g} / \mathrm{l}$, Yeast extract $0.5 \mathrm{~g} / \mathrm{l}$, Dextrose \\
\hline $\begin{array}{l}\text { Enrichment } \\
\text { media }\end{array}$ & Peptone $2.5 \mathrm{~g} / \mathrm{l}$, Yeast extract $0.5 \mathrm{~g} / \mathrm{l}$, Dextrose \\
\hline
\end{tabular}

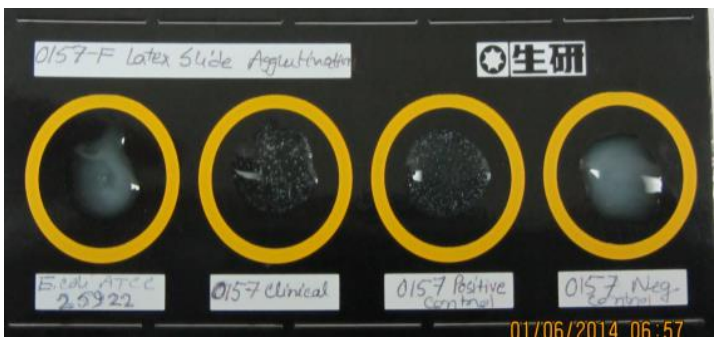

Fig. 1: Latex slide agglutination test. In this figure on the first circle non 0157 E. coli strain (ATCC 25922) did not show agglutination as well as on the forth circle E. coli $\mathrm{O} 157$ negative control (supplied with the agglutination kit). On the second circle, representative clinical E. coli $\mathrm{O} 157$ isolate showed agglutination like E. coli $\mathrm{O} 157$ positive control on third circle (supplied with the agglutination kit).

Prevalence rate of $E$. coli 0157 in samples

Six FCD-H samples were collected and among them three samples were positive for E. coli $\mathrm{O} 157$ (50\%), whereas one among three FCD-S samples was positive for E. coli $\mathrm{O} 157$ (33.33\%). For both the case of CCD and SCD samples, two among three samples were positive for $E$. coli $\mathrm{O} 157$ (66.67\%) (Fig. 2 and Supplementary Table 2).

Table-2: Prevalence rate of fresh cow dung hard, soft, composting cow dung and soil of cow shade samples by the presence or absence of $E$. coli 0157

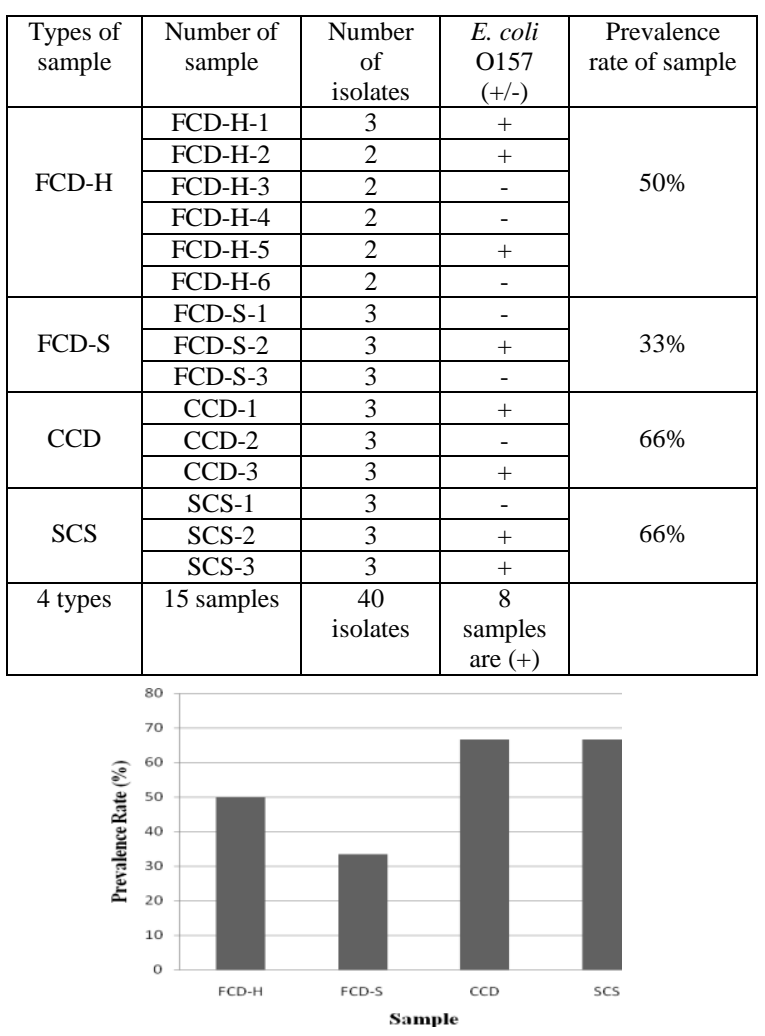

Fig. 2: Prevalence rate of $\boldsymbol{E}$. coli $\mathrm{O157}$ in samples. This fig. indicates FCD-H, Fresh cow dung hard; FCD-S, Fresh cow dung soft; CCD, Composting cow dung; SCS, Soil of cow shade. The prevalence rate of fresh cow dung (hard) sample is 50\%, fresh cow dung (soft) sample is $33.33 \%$, composting cow dung sample is $66.67 \%$, and soil of cow shade sample is $66.67 \%$. 


\section{Discussion}

Escherichia coli $\mathrm{O} 157$ is a Shiga toxin producing E. coli (STEC), causing endemic food and waterborne diseases in human with a spectrum of illnesses ranging from asymptomatic carriage and diarrhea to fatal hemolytic uremic syndrome. Outbreaks of E. coli 0157 infections are often associated with municipal water supply, swimming in contaminated water, consuming undercooked meat and meat products specially beef and even direct animal contact. This study was aimed to isolate and identify $E$. coli of bovine origin and screen the O157 serotype among the isolates. Cow dung was selected as the sample of choice for this study because cattle are main reservoir of Shiga toxin-producing E. coli O157 (STEC) (Eppinger et al., 2011). The another reason behind this choice is that cowdung has been used frequently in household carelessly and pose threat of contamination. Interestingly greater occurrence of $E$. coli 0157 were observed in composting cow dungs as well as soils near the cow sheds rather than fresh cow dung. Though the resulting decimal reduction times of $E$. coli $\mathrm{O} 157$ has been reported to be ranged from 6 days to 3 weeks in manure and from 2 days to 5 weeks in manure slurry (Himathongkham et al., 1999), this study indicates the strains' adaptive and survival potential in environmental condition. Composts and soils used to accumulate this strain over time from the dung of a variety of cows and thus posing threat of reinoculation and colonization to new cows as well as continuous shedding to the environment.

The carriage and shedding of E. coli $\mathrm{O} 157$ did not differ with season but differed among groups of cattle and among breeds of cattle in a tropical country (Akanbi et al., 2011). In North America, Japan and parts of Europe, most outbreaks are due to EHEC serotype O157:H7, whereas other serotypes are important health concerns in other developed countries (Kaper et al., 2004). In the ten years following the 1982 outbreak, approximately thirty outbreaks were recorded in the United States (Griffin and Tauxe, 1991). Though, EHEC occurs in all countries, the incidence seems to vary between countries. In Bangladesh, no major outbreak due to E. coli $\mathrm{O} 157$ has been reported but it does not imply its absence. However most of the areas of our country are merely been surveyed and diseases are either home treated or even hospitalized without investigation and proper reporting. Thus reports on the prevalence or reservoir status of our domestic ruminants with E. coli $\mathrm{O} 157$ are a lavish thinking in Bangladesh. This study was an approach to have a look in the carriage status of cattle in three small rural communities and to assess the risks associated with it. Though, the Shiga toxins or associated genes were not assessed in the study and the isolates were non-haemolytic, this study cannot claim the virulence of 0157 strains. However, the presence of E. coli O157 serotype still should allege attention and implies public health concern to handle livestocks, its' wastes and products..

\section{Conclusion}

The study isolated and serologically identified E. coli $\mathrm{O} 157$ of bovine origin from cow dung and cow-shed soil. The occurrence of E. coli O157 was found unpredictably high but the sample size was too small to delineate a statistical significance of the result. But the result could urge the emergency of such risk assessment. A nationwide survey should be performed to confirm the virulence trait of bovine E. coli O157 strains and a correlation of diseases within vulnerable communities.

\section{References}

Akanbi BO, IP Mbah and PC Kerry, 2011. Prevalence of Escherichia coli $\mathrm{O} 157: \mathrm{H7}$ on hides and faeces of ruminants at slaughter in two major abattoirs in Nigeria. Lett Appl Microbiol, 53(3): 336340 .
Arthur TM, DM Brichta-Harhay, JM Bosilevac, N Kalchayanand, SD Shackelford, TL Wheeler and M Koohmaraie, 2010. Super shedding of Escherichia coli O157:H7 by cattle and the impact on beef carcass contamination. Meat Sci, 86(1): 32-37.

Cernicchiaro N, DL Pearl, SA McEwen, HN Zerby, FL Fluharty, SC Loerch, MD Kauffman, JL Bard and JT LeJeune, 2010. A randomized controlled trial to assess the impact of dietary energy sources, feed supplements, and the presence of supershedders on the detection of Escherichia coli $\mathrm{O} 157: \mathrm{H} 7$ in feedlot cattle using different diagnostic procedures. Foodborne Pathog Dis, 7(9): 1071-1081.

Chapman PA, 1989. Evaluation of commercial latex slide test for identifying Escherichia coli O157. J Clin Pathol, 42(10): 11091110.

Cheesbrough M, 1985. Medical laboratory manual for tropical countries. Vol. Microbiology, pp. 400-480.

Diaz S, D Vidal, S Herrera-Leon and S Sanchez, 2011. SorbitolFermenting, beta-Glucuronidase-Positive, Shiga ToxinNegative Escherichia coli O157:H7 in Free-Ranging Red Deer in South-Central Spain. Foodborne Pathog Dis,

Eppinger M, MK Mammel, JE Leclerc, J Ravel and TA Cebula, 2011. Genome signatures of Escherichia coli O157:H7 isolates from the bovine host reservoir. Appl Environ Microbiol, 77(9): 29162925.

Fischer Walker CL, MJ Aryee, C Boschi-Pinto and RE Black, 2012. Estimating Diarrhea Mortality among Young Children in Low and Middle Income Countries. PLoS One, 7(1): e29151.

Griffin PM and RV Tauxe, 1991. The epidemiology of infections caused by Escherichia coli O157:H7, other enterohemorrhagic E. coli, and the associated hemolytic uremic syndrome. Epidemiol Rev, 13: 60-98.

Himathongkham S, S Bahari, H Riemann, D Cliver, 1999. Survival of Escherichia coli $\mathrm{O} 157: \mathrm{H} 7$ and Salmonella typhimurium in cow manure and cow manure slurry. FEMS Microbiol Lett, 178(2): 251-257.

Jeong KC, MY Kang, J Kang, DJ Baumler and CW Kaspar, 2011. Reduction of Escherichia coli $0157: \mathrm{H} 7$ shedding in cattle by addition of chitosan microparticles to feed. Appl Environ Microbiol, 77(8): 2611-2616.

Kaper JB, JP Nataro and HL Mobley, 2004. Pathogenic Escherichia coli. Nat Rev Microbiol, 2(2): 123-140.

Karch H, PI Tarr and M Bielaszewska, 2005. Enterohaemorrhagic Escherichia coli in human medicine. Int $\mathrm{J}$ Med Microbiol, 295(6-7): 405-418.

Lim JY, J Yoon and CJ Hovde, 2010. A brief overview of Escherichia coli O157:H7 and its plasmid O157. J Microbiol Biotechnol, 20(1): 5-14.

Nripendra S, 2012. Waste or Resource? Indigenous Uses of Cow Dung and Urine in Rural India. The Pennsylvania State University Interinstitutional Consortium for Indigenous Knowledge, https://www.libraries.psu.edu/psul/icik/wasteorresource.html.

Seker E, Y Kuyucuoglu, B Sareyyupoglu and H Yardimci, 2010. PCR detection of Shiga toxins, enterohaemolysin and intimin virulence genes of Escherichia coli $0157: \mathrm{H} 7$ strains isolated from faeces of Anatolian water buffaloes in Turkey. Zoonoses Public Health, 57(7-8): e33-37.

Stanford K, TA McAllister, YD Niu, TP Stephens, A Mazzocco, TE Waddell and RP Johnson, 2010. Oral delivery systems for encapsulated bacteriophages targeted at Escherichia coli O157:H7 in feedlot cattle. J Food Prot, 73(7): 1304-1312.

Tarr PI, 1995. Escherichia coli O157:H7: clinical, diagnostic, and epidemiological aspects of human infection. Clin Infect Dis, 20(1): 1-8; quiz 9-10.

van Overbeek LS, E Franz, AV Semenov, OJ de Vos and AH van Bruggen, 2010. The effect of the native bacterial community structure on the predictability of $E$. coli $\mathrm{O} 157: \mathrm{H} 7$ survival in manure-amended soil. Lett Appl Microbiol, 50(4): 425-430. 
Vande Walle K, MA Yekta, F Verdonck, L De Zutter and E Cox, 2011. Rectal inoculation of sheep with E. coli O157:H7 results in persistent infection in the absence of a protective immune response. Vet Microbiol, 147(3-4): 376-382.

Vilte DA, M Larzabal, S Garbaccio, M Gammella, BC Rabinovitz, AM Elizondo, RJ Cantet, F Delgado, V Meikle, A Cataldi and EC Mercado, 2011. Reduced faecal shedding of Escherichia coli O157:H7 in cattle following systemic vaccination with gammaintimin C and EspB proteins. Vaccine, 29(23): 3962-3968.

Yekta MA, E Cox, BM Goddeeris and D Vanrompay, 2011. Reduction of Escherichia coli $\mathrm{O} 157: \mathrm{H} 7$ excretion in sheep by oral lactoferrin administration. Vet Microbiol, 150(3-4): 373-378. 